\title{
Process Design Study of Reversible Solid Oxide Cell (r-SOC) System for Coupling Energy Storage and Hydrogen Economy Supply Chain
}

\author{
S. Santhanam, M. P. Heddrich, M. Riedel, K. A. Friedrich \\ German Aerospace Center (DLR), Institute for Engineering Thermodynamics \\ Pfaffenwaldring 38-40, 70569 Stuttgart, Germany
}

\begin{abstract}
The reversible Solid Oxide Cell (r-SOC) system is capable of addressing the challenges of energy storage and sector coupling. Coupling highly efficient endothermic electrolysis operation and exothermic fuel cell operation allows of higher roundtrip efficiencies. Therefore thermal integration, storage and management between the two modes of operation are crucial. In this study, a process system study of an r-SOC electrochemical reactor system is performed. Process system analysis is performed based on experimental investigation of a commercially available $\mathrm{r}$ SOC reactor carried out under pressurized conditions. Opportunities of integrating thermal energy storage are investigated. Detailed process system architectures are discussed and effects of key system operating parameters are analyzed. Achievable system roundtrip efficiencies for the different scenarios using currently available r-SOC reactor technology are quantified
\end{abstract}

\section{Introduction}

Higher penetration of renewable energy sources in the energy mix and increasing pressure to decarbonize society introduces new challenges. Energy storage and grid stabilization systems are necessary to address the intermittent nature of renewable energy sources (wind, solar etc.) (1-3). Renewable energy storage in form of hydrogen offers an attractive option for energy storage $(4,5)$. With advent of hydrogen economy and growing number of fuel cell vehicles, local production and supply of hydrogen infrastructure for refueling stations is essential (6-8).

An r-SOC electrochemical reactor system is capable addressing these multiple challenges of energy storage and coupling the energy storage sector with hydrogen economy sector. Electricity storage is achieved by operating such a system in electrolysis mode (reduction of $\mathrm{H} 2 \mathrm{O}$ ). Electrical energy is converted to chemical energy in form of hydrogen. The produced hydrogen can be supplied into gas grids or stored locally which can be supplied to hydrogen refueling stations. During high demand for electricity, the system can be switched to fuel cell mode during which the stored hydrogen is efficiently converted to electricity. r-SOC systems offer an interesting feasible solution for the following challenges: 1) Efficient electricity storage, 2) Grid stabilization required for intermittent renewable energy, 3) Sector coupling of energy storage sector with hydrogen economy supply chain and 4) A decentralized solution for the above challenges via e.g. hydrogen refueling stations. 
An r-SOC system as described above poses certain challenges. The requirement for a standalone SOEC or SOFC systems are different. Integrating the SOFC and the SOEC into one single system provides additional constraints. Typically, a SOEC system is normally operated in an exothermic or thermoneutral operation mode. This results in process efficiency around $75 \%$ in SOEC mode and 55\% in SOFC mode, thereby leading to a roundtrip efficiency of $40 \%$ (9). By shifting the SOEC operation of the r-SOC system to the endothermic mode, higher roundtrip efficiency can be attained. Therefore thermal management and storage between the two modes of operation are crucial. A commercially available r-SOC reactor is experimentally characterized under pressurized operation conditions. Process systems are developed based on the commercial r-SOC reactor and opportunities for thermal management are discussed. The system performances are quantified under different operation conditions.

\section{Experimental Analysis}

A commercially available r-SOC reactor was experimentally characterized with DLR's pressurized test rig facility. The experiments were performed in both SOFC and SOEC operation at pressures of 1 to 8 bar. At different pressures, the U(i) characteristic curve and the Electrochemical Impedance Spectroscopy (EIS) was performed at different reactor temperatures from $700^{\circ} \mathrm{C}$ to $850^{\circ} \mathrm{C}$. The commercial r-SOC reactor is a 10 layer, electrolyte supported cell (ESC) stack with an open air side design. The electrolyte layer is made of $8 \mathrm{~mol} \%$ Yttria stabilized Zirconia (YSZ) and has thickness of $90 \mu \mathrm{m}$. The fuel electrode is a matrix of Nickel (Ni) with Gadolinium doped Ceria (GDC) and has a thickness of $30 \mu \mathrm{m}$. The air electrode is a Lanthanum Strontium Cobalt Ferrate (LSCF) layer with a GDC protective coating between the electrode and the electrolyte. The total thickness of the air electrode is $55 \mu \mathrm{m}$. The EIS measurements were performed at the Open Circuit Voltage (OCV) to quantify the ohmic losses of the r-SOC reactor.

In the SOFC mode, experiments were performed with a gas mixture of $60 \% \mathrm{H}_{2}$ and $40 \% \mathrm{~N}_{2}$. At maximum current, a fuel utilization of $60 \%$ and air utilization of $25 \%$ was maintained. In the SOEC operation mode, the dynamic U(i) measurements were performed with a feed supply of $10 \mathrm{~mol}^{\%} \mathrm{H}_{2}$ and $90 \mathrm{~mol} \% \mathrm{H}_{2} \mathrm{O}$. The r-SOC reactor performance obtained from the experimental analysis was used for the system modeling.

\section{System Modeling}

The simplified process flow diagrams of the r-SOC system during the SOFC operation and the SOEC operation are depicted in Figure 1 and Figure 2 respectively. The hydrogen fuel is stored in a pressurized tank at 25 bar and a temperature of $25^{\circ} \mathrm{C}$. Water is stored within the system as liquid at atmospheric pressure and temperature of $50{ }^{\circ} \mathrm{C}$. During the SOFC operation mode, hydrogen is supplied to the system at the system operating pressure. It is then preheated in the heat recovery unit. The heat fuel is then mixed with the fuel exhaust recycle loop. Fuel exhaust recycle loop is employed to achieve a higher overall fuel conversion ratio. The fuel mixture is the finally heat to the fuel inlet temperature of $750{ }^{\circ} \mathrm{C}$ required for the r-SOC reactor in the SOFC operation mode. The air required for the hydrogen oxidation and cooling of the r-SOC reactor in SOFC operation is supplied from the ambient. Based on the system operation it is either 
compressed or supplied at atmospheric pressure. Air is preheated in the heat recovery unit. Depending on the requirement is it mixed with the air exhaust recycle stream. The final air mixture is supplied to the reactor at inlet temperature of $700{ }^{\circ} \mathrm{C}$. The fuel and air exhaust from the r-SOC reactor is fed to the heat storage units. The heat produced during the SOFC operation is stored in a two stage heat storage units at $850{ }^{\circ} \mathrm{C}$ and $750{ }^{\circ} \mathrm{C}$. Finally, the remaining heat in the exhaust stream is extracted in the heat recover units. Unused hydrogen is separated from water and fed back to the hydrogen tank. Air is expanded to environment pressure and released to the environment.

During the SOEC operation, the water stored in the water tank is fed to the system as a reactant. The water is preheated and evaporated in the economizer and evaporator sections of the heat recover unit. Hydrogen is mixed with the steam resulting in $10 \mathrm{~mol} \%$ of hydrogen in the steam mixture. Hydrogen is added to the inlet reactants in SOEC operation to prevent oxidation of nickel in the fuel electrode. The steam reactant mixture is passed to the heat storage units where it is preheated to the inlet temperature of $820{ }^{\circ} \mathrm{C}$ for the fuel reactant side of the r-SOC reactor during SOEC operation. Air supplied to the system as a sweep gas to remove the oxygen produced during the SOEC operation. Air is compressed to the system pressure and preheated in the heat recovery units. It is passed to the heat storage unit where is it absorbs the heat required for endothermic electrochemical reaction and is preheated to inlet temperature of $820{ }^{\circ} \mathrm{C}$. Apart from acting as a sweep gas, air supplied to the reactor plays the role of heat transfer medium. The hydrogen product gas and air from the r-SOC reactor during the SOEC operation is cooled in the heat recovery units. The hydrogen is separated from unused water and fed to hydrogen fuel tank. Air is expanded to the atmospheric pressure and released to the environment.

\section{Assumptions}

The following assumptions were made for the system analysis

1. A symmetric operation of the r-SOC system is considered. The duration of the charging process (SOEC process) is equal to the duration of discharging process (SOFC process).

2. The charge transferred during the SOFC operation (oxygen ions from air to fuel side) is equal to the charge transferred during the SOEC operation (oxygen ions from fuel to air side).

3. Assumptions 1 and 2 result in equal current during the SOFC and SOEC operations.

\section{$\underline{\text { Heat Storage }}$}

A latent heat storage system (LHS) is considered within this analysis. The LHS system exploits the heat of fusion during phase change of a material to store heat. The material undergoes a phase transition during charging and discharging process. Such materials are called as the Phase Change Materials (PCM). A two stage cascaded heat storage system is considered. The first stage heat storage (HTPCM) occurs at a temperature of $850{ }^{\circ} \mathrm{C}$ and second stage heat storage (LTPCM) at $750{ }^{\circ} \mathrm{C}$. The PCM materials are selected based on literature study. Fluoride salts are suitable candidates at these temperatures with melting point in the range of $750-900{ }^{\circ} \mathrm{C}(10)$. 


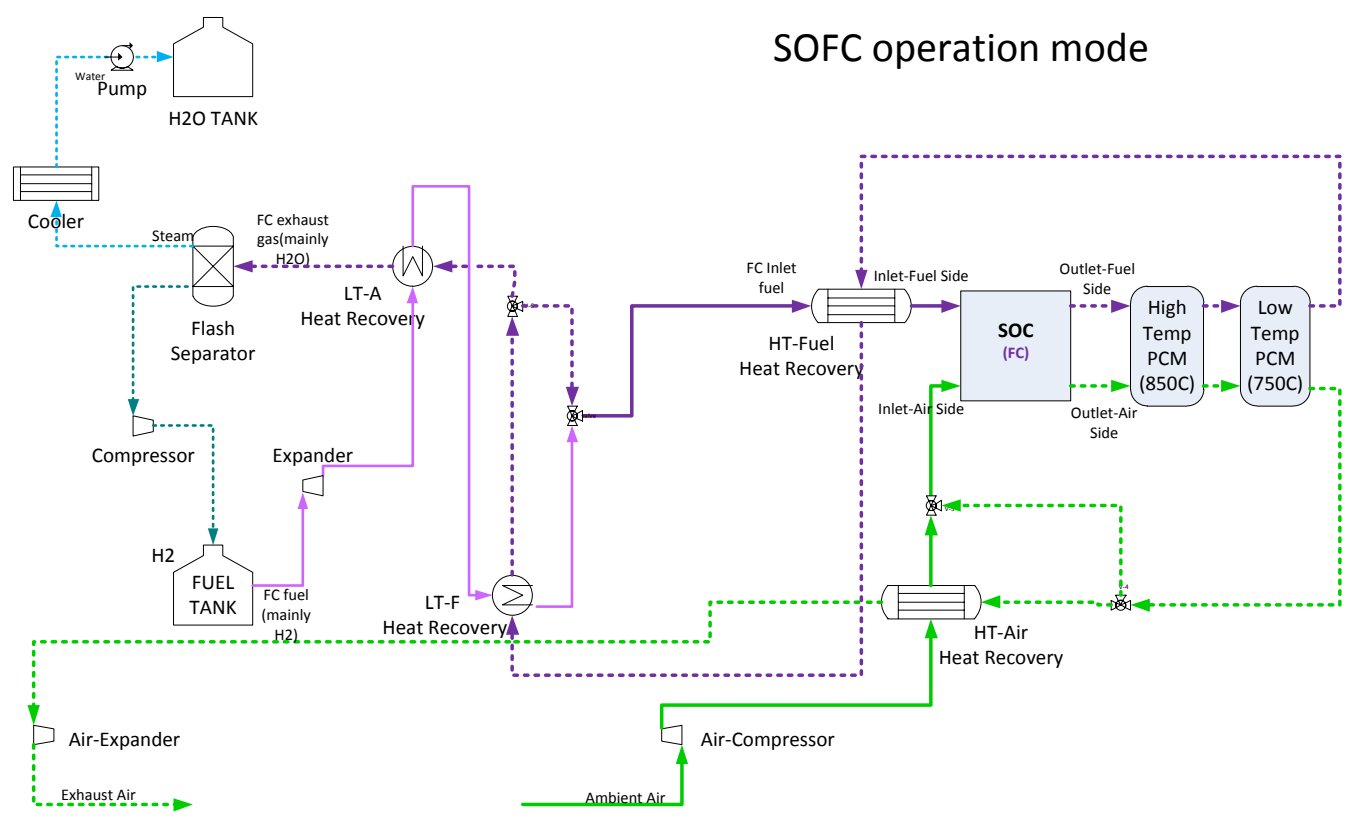

Figure 1. Process flow diagram of the hydrogen based r-SOC system during the SOFC operation mode of the system. Solid lines represent the reactant/inlet flows entering the $\mathrm{r}$ $\mathrm{SOC}$ reactor. Dotted lines represent the product/outlet flows leaving the r-SOC reactor

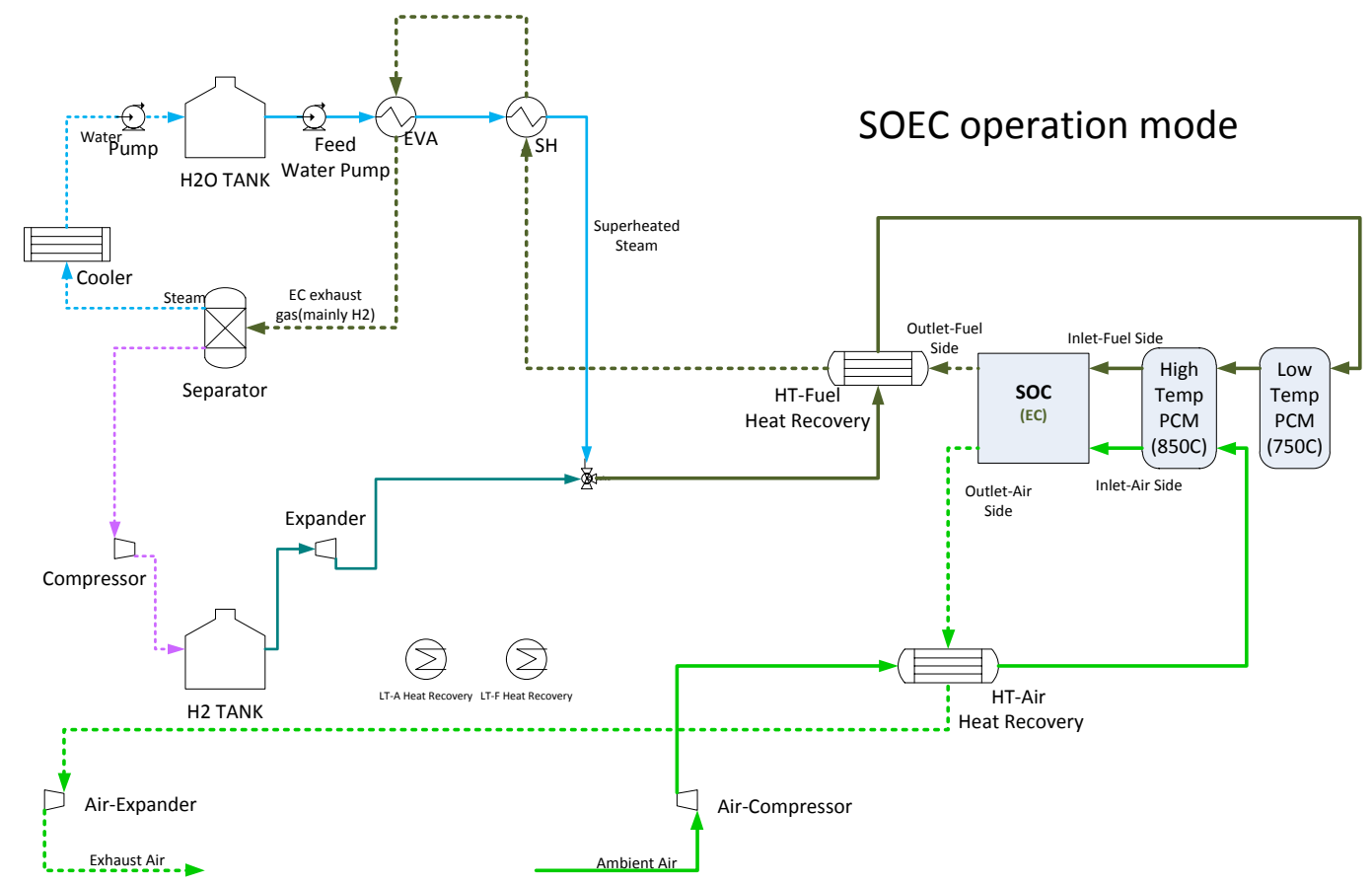

Figure 2. Process flow diagram of the hydrogen based r-SOC system during the SOFC operation mode of the system. Solid lines represent the reactant/inlet flows entering the $\mathrm{r}$ $\mathrm{SOC}$ reactor. Dotted lines represent the product/outlet flows leaving the r-SOC reactor.

\section{Results}

The results of the analysis are presented in brief in this section. The following performance parameters were defined to quantify the system performance: 
- Reactor roundtrip efficiency $\left(\eta_{\mathrm{rt}, \mathrm{soc}}\right)$ : Ratio of work produced by the reactor during the SOFC operation to work consumed by the reactor during SOEC operation

- System roundtrip efficiency $\left(\eta_{\mathrm{rt}, \mathrm{sys}}\right)$ : Ratio of the net-work produced (including balance of plan consumption) by the r-SOC system during the SOFC operation to net-work consumed (including balance of plan consumption) by the r-SOC system during the SOEC operation.

- Heat ratio $(\theta)$ : Ratio of heat consumed by the reactor/system from the heat storage during SOEC operation to heat stored in the heat storage system during the SOFC operation mode.

\section{Performance of r-SOC Reactor}

From the experimental analysis of the r-SOC reactor, the ohmic component of the electrochemical losses was found to be the most dominant. The obtained result is consistent for an electrolyte supported cell design SOFC or SOEC reactor reported in literature. Hence a temperature dependent semi empirical model was utilized for the rSOC reactor within the system model. The ohmic component was found to be $80 \%$ of the total losses at all operational conditions.

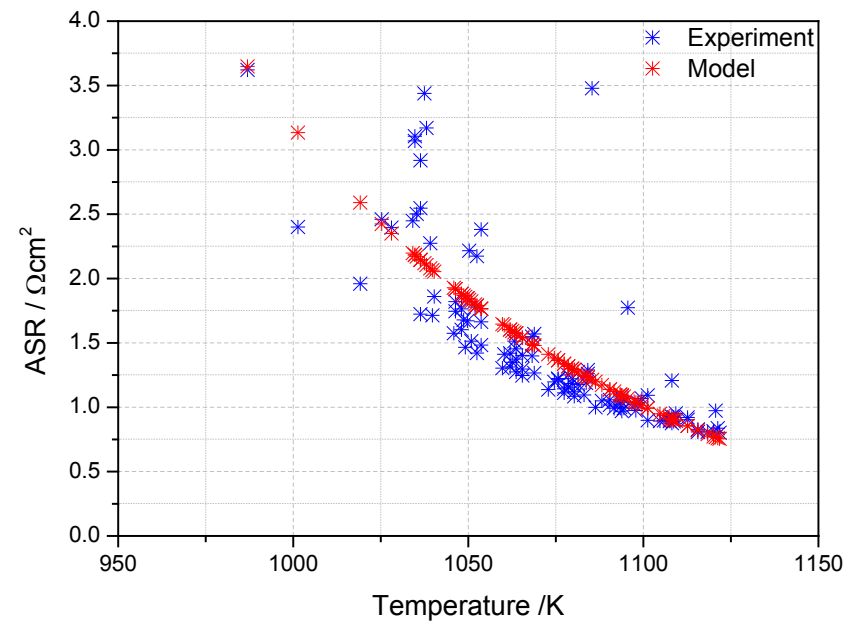

Figure 3. The area specific resistance (ASR) of the commercial r-SOC reactor was obtained as function of temperature. The figure shows the ASR obtained from experiments versus the ASR calculated using a semi empirical temperature dependent function.

\section{Process System Performance}

The process system behavior was evaluated at atmospheric pressure and pressurized operation. The r-SOC system was operated at current density of $2500 \mathrm{~A} / \mathrm{m}^{2}$. The roundtrip efficiency of the reactor and system at the different system operation pressures is provided in the Table 1

TABLE I. System performance of hydrogen based r-SOC process system

\begin{tabular}{ccc}
\hline Parameter & $\mathbf{1}$ bar & $\mathbf{2 5}$ bar \\
\hline Reactor roundtrip efficiency & $56 \%$ & $62 \%$ \\
System roundtrip efficiency & $52 \%$ & $53 \%$
\end{tabular}


Non-Pressurized Operation. During the SOFC operation at 1 bar, a total system fuel utilization of $90 \%$ was obtained. The fuel exhaust recycle ratio was fixed at $11 \%$. The average reactor temperature of r-SOC reactor during the SOFC operation was $845^{\circ} \mathrm{C}$. The mass flow rate of fuel supplied to the system corresponds to input chemical power of 100 $\mathrm{kW}$. Out of the $100 \mathrm{~kW}$ chemical power supplied to the system, $50 \mathrm{~kW}$ of electrical power and $49 \mathrm{~kW}$ of thermal power were produced. The remaining $11 \mathrm{~kW}$ accounts for unreacted fuel in the exhaust stream. Thermal energy stored in the heat storage system accounted to $24 \mathrm{~kW}$ of which, $5 \mathrm{~kW}$ was stored at HTPCM and $19 \mathrm{~kW}$ in LTPCM. During the SOEC operation at $1 \mathrm{bar}, 100 \mathrm{~kW}$ of chemical power was produced. The electrical energy input constituted $87 \mathrm{~kW}$ and thermal energy only $2 \mathrm{~kW}$ of the total chemical power produced. This implies that the r-SOC reactor was only slightly endothermic in the SOEC process. Still, $21 \mathrm{~kW}$ of thermal power was consumed from the heat storage tanks during the SOEC process. This highlights the major role of heat storage. Apart from supporting endothermic SOEC process, it also provides the heat required for process heating and steam generation. The average r-SOC reactor temperature during the SOEC process was determined to be $810^{\circ} \mathrm{C}$.

Pressurized Operation. At pressurized operation of 25 bar, $56 \mathrm{~kW}$ of electrical power and $33 \mathrm{~kW}$ of thermal power is produced. The heat produced during the SOFC operation at 25 bar is less than at non pressurized conditions. This allows storing only $21 \mathrm{~kW}$ of thermal power in the heat storage unit. The average reactor temperature was determined to be $845{ }^{\circ} \mathrm{C}$. During the SOEC operation at $25 \mathrm{bar}$, out of $100 \mathrm{~kW}$ of chemical power produced, $88.5 \mathrm{~kW}$ was supplied in the form of electrical power and only $0.5 \mathrm{~kW}$ was supplied as thermal power. The r-SOC reactor is close to thermoneutral operation point during the SOEC process. But still almost $20 \mathrm{~kW}$ of thermal power was consumed from the heat storage tank. Therefore even during a thermoneutral operation point, a significant amount of thermal power from the heat storage tank is consumed. This further highlights the key role of the thermal management system in the r-SOC system

The pressurized operation improves the r-SOC reactor performance leading to an increase in the roundtrip efficiency of the reactor. The effect is purely due to thermodynamic behavior. At higher operational pressures the thermodynamic ideal voltage of increases. The higher thermodynamic voltage is beneficial for the SOFC process but not favorable for the SOEC process. For the r-SOC process, the positive effect of pressure in the SOFC operation compensates for the negative effect for the SOEC process. Hence in turn leads to a higher roundtrip efficiency of the reactor. From the experimental analysis, it was observed that the effect of temperature was more dominant than the effect of pressure. Due to the ESC reactor design, the ohmic losses are dominant and pressure doesn't affect the ohmic resistance. Hence, effect of pressure on electrochemical losses leading was ruled out as a reason for high reactor roundtrip efficiency at 25 bar.

The system roundtrip efficiency is lower than reactor roundtrip efficiency in both conditions. This is due to the work consumption of the balance of plant components (BoP). For the system at 1 bar, the BoP work consumption was higher during the SOEC operation. Since, the hydrogen produced during the SOEC process must be compressed from 1 bar to gas storage tank pressure of 25 bar. Whereas at 25 bar, the BoP work consumption was higher during the SOFC process. This is because; the air required has to be compressed from the ambient pressure to system pressure. The volume flow rate of air 
required during the SOFC process is higher than in SOEC process due to higher heat production in the SOFC process. Hence, the leading to higher BoP work consumption in the SOFC process at 25 bar. Hence, the compression of air is more energy intensive than downstream compression of hydrogen for 1 bar system. Pressurized operation has a positive effect on reactor roundtrip efficiency but not beneficial for the system performance. More complex system designs are required to increase the system performance for pressurized operation.

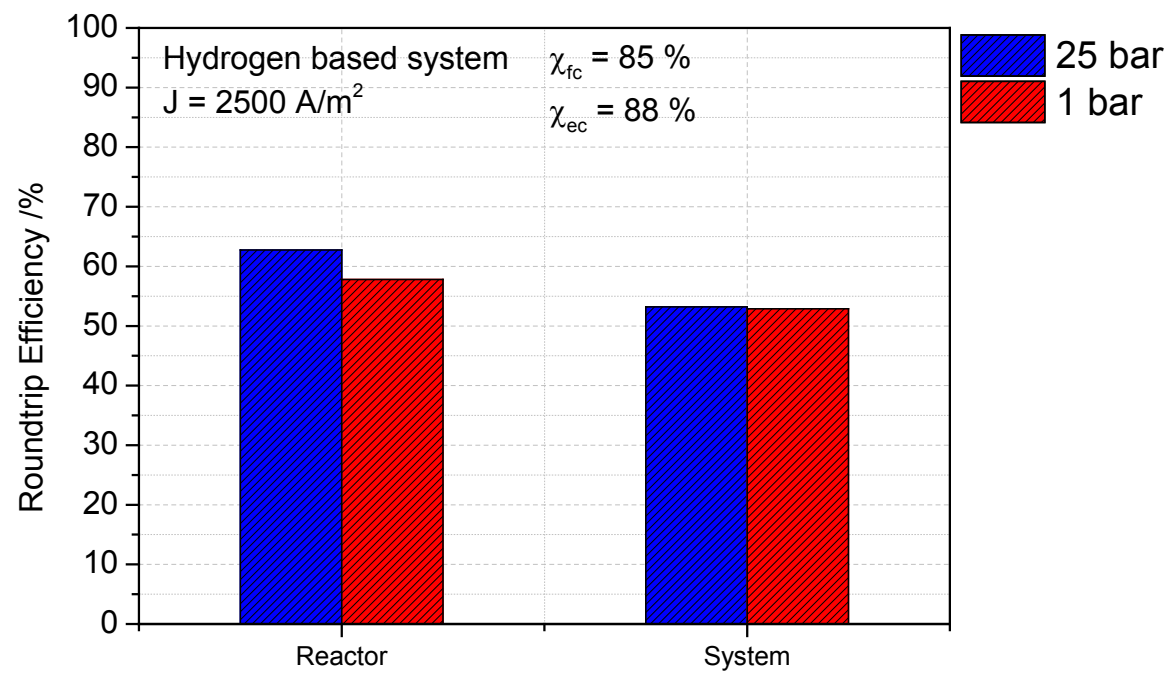

Figure 4. The roundtrip efficiency of the r-SOC reactor and system of hydrogen based system at non pressurized operation and pressurized operation at 25 bar.

Thermal Management. As discussed earlier, the thermal management system plays a key role in the system performance for pressurized and non-pressurized operation. Even during a thermonetural operation of the r-SOC reactor during the SOEC operation mode, $98 \%$ of the heat stored in the heat storage during the SOFC operation was consumed during SOEC operation. The heat ratio () for the r-SOC system is shown in the Figure 5.

$\theta$ - Ratio of heat consumed in SOEC mode to heat stored in SOFC

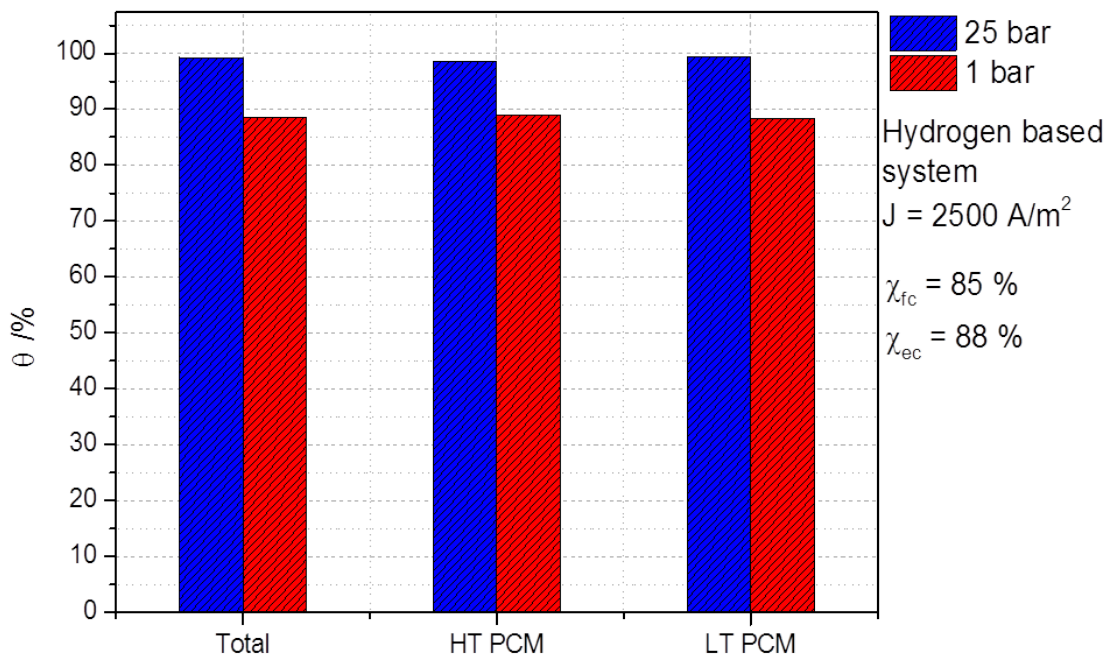

Figure 5. Heat ratio of the hydrogen based r-SOC process system. The total heat ratio and heat ratio of the HTPCM and LTCPM are shown for non-pressurized and pressurized operation. 
At non pressurized conditions, $88 \%$ of the heat stored was consumed during the SOEC operation. At 25 bar, $98 \%$ of the heat stored was consumed. At 25 bar, less heat is produced during the SOFC operation and hence less heat is stored in the heat stored as compared to non-pressurized system. Even though the r-SOC reactor is close to thermoneutral operation during the SOEC process, the heat required for process heating and steam generation is more or less the same at 1 bar and 25 bar. Therefore the heat ratio is higher for the pressurized operation than for the non-pressurized operation.

\section{Conclusion}

An r-SOC process system for coupling energy storage and hydrogen economy was developed based on a commercial r-SOC reactor. The possibility of endothermic operation during the SOEC process was investigated. It was shown that an endothermic operation in SOEC process can lead to higher roundtrip efficiencies. An efficient thermal management system was proposed to enable endothermic operation of the SOEC process. The importance of the thermal management system in achieving higher roundtrip efficiency was further highlighted.

\section{References}

1. P. J. Hall and E. J. Bain, Energy Policy, 36(12), 4352-4355, (2008).

2. H. Ibrahim, A. Ilinca, and J. Perron, Renew. Sustain. Energy Rev., 12(5),. 12211250, (2008).

3. A. Evans, V. Strezov, and T. J. Evans, Renew. Sustain. Energy Rev., 13(5), 10821088, (2009).

4. A. Sternberg and A. Bardow, Energy Environ. Sci., 8(2), 389-400 (2015).

5. H. Chen, T. N. Cong, W. Yang, C. Tan, Y. Li, and Y. Ding, Prog. Nat. Sci., 19(3), 291-312, (2009).

6. J. A. Turner, Science, 305(5686), 972-974, (2004).

7. M. Ball and M. Wietschel, 34(2), 615-627, (2009).

8. G. Mulder, J. Hetland, and G. Lenaers, Int. J. Hydrogen Energy, 32(10-11), 1324-1331, (2007).

9. J. Mermelstein and O. Posdziech, 306, 59-70 (2016).

10. Zalba, B., Marín, J.M., Cabeza, L.F. and Mehling, H., Applied Thermal Engineering, 23(3), 251-283 (2003). 